\title{
Survey of Japanese physicians' attitudes towards the care of adult patients in persistent vegetative state
}

Atsushi Asai, Munetaka Maekawa, Ichiro Akiguchi, Tsuguya Fukui, Yasuhiko Miura, Noboru Tanabe and Shunichi Fukuhara Kyoto University School of Medicine, fapan and Monash University, Australia, Kobe University Research Center for Urban Safety and Security, Kobe, fapan, Kyoto University School of Medicine, fikei University School of Medicine, Kyoto University School of Law and the University of Tokyo Faculty of Medicine, respectively

\begin{abstract}
Objectives-Ethical issues have recently been raised regarding the appropriate care of patients in persistent vegetative state (PVS) in Fapan. The purpose of our study is to study the attitudes and beliefs of Fapanese physicians who have experience caring for patients in PVS.

Design and setting-A postal questionnaire was sent to all 317 representative members of the fapan Society of Apoplexy working at university hospitals or designated teaching hospitals by the Ministry of Health and Welfare. The questionnaire asked subjects what they would recommend for three hypothetical vignettes that varied with respect to a PVS patient's previous wishes and the wishes of the family.

Results-The response rate was $65 \%$. In the case of a PVS patient who had no previous expressed wishes and no family, $3 \%$ of the respondents would withdraw artificial nutrition and hydration $(A N H)$ when the patient did not require any other life-sustaining treatments, $4 \%$ would discontinue $A N H$, and $30 \%$ would withhold antibiotics when the patient developed pneumonia. Significantly more respondents (17\%) would withdraw ANH in the case of a PVS patient whose previous wishes and family agreed that all life support be discontinued. Most respondents thought that a patient's written advance directives would influence their decisions. Forty per cent of the respondents would want to have ANH stopped and $31 \%$ would not want antibiotics administered if they were in PVS.

Conclusions-Fapanese physicians tend not to withdraw ANH from PVS patients. Patients'written advance directives, however, would affect their decisions.
\end{abstract}

(Fournal of Medical Ethics 1999;25:302-308)

Keywords: Japan; persistent vegetative state; physician; person; resource allocation; life prolongation

\section{Introduction}

Physicians responsible for the management of patient in a persistent vegetative state (PVS) face quite a few problems. These include decidin whether artificial nutrition and hydration (ANH is treatment or nutritional care; whether withos drawal of tube feeding is an appropriate form of management; at what level of awareness a patiense can be said to have a positive quality of life, and who should determine a patient's right to die. ' How to evaluate the value of a mere biological life is also one of the significant problems. Some mati disagree sharply as to what the response should $b \stackrel{8}{\circ}$ to these problems, while people from different countries may have different beliefs with regard to the essence of medical care for PVS patients.

In the United States, several studies have confirmed that the majority of patients $(85 \%$ $95 \%$ ) do not wish to be maintained in permanently unconscious state. ${ }^{3-5}$ In the Unite Kingdom, the House of Lords decided that it was not unlawful to withdraw $\mathrm{ANH}$ from Anthong Bland. ${ }^{6}$ Surveys conducted in these countries also demonstrated that the majority of physicians cono sidered it appropriate not to treat active infectio and other life-threatening conditions and to with draw ANH from PVS patients. ${ }^{7}$ Some physicians even considered that it would be ethical to haster PVS patients' death by lethal injection. ${ }^{8}$ People in some countries seem to share the opinion that an unconscious human being is no more a persor and that mere biological life can benefit nothing from medical care. Those who believe so woulch find care for PVS patients meaningless ox pointless.

In Japan, on the other hand, a public opiniox poll by the Ministry of Health and Welfar 8 revealed that approximately $30 \%$ of respondents surveyed thought all life support, including ANH should be discontinued, but the majority reo sponded that only extraordinary intervention suck 
as mechanical ventilation should be withdrawn. ${ }^{9}$ As far as the attitudes of physicians as caregivers are concerned, no national survey or study has ever been conducted. Thus there are no data regarding whether the general public and physicians agree on appropriate care of such patients or whether Japanese physicians have different opinions from those in the United States and the United Kingdom. The Japanese may have significantly different concepts about human life and death, and about what constitutes a valuable life. If this is so, different social norms about beneficial medical care and the goals of medicine would lead to distinctive practices in clinical settings.

The purpose of our survey was, therefore, to know the attitudes of Japanese physicians involved in managing PVS patients. We were especially interested in the decisions that might lead to the patient's death and what factors and whose wishes would influence such decisions.

\section{Methods and subjects}

We surveyed all representative members of the Japan Society of Apoplexy working at university hospitals or hospitals officially designated by the Ministry of Health and Welfare as teaching institutions. We decided to survey them because they are most likely to be involved in the long term management of PVS patients and have played a leading role in under- and post-graduate clinical education at their medical schools or institutions. A postal questionnaire was sent to all 317 representative members of the society.

\section{Questionnaire}

The nine-page questionnaire consisting of three parts took about 15 minutes to complete. The first section included four vignettes on the following hypothetical case:

You are taking care of a male patient in his 70 s in persistent vegetative state (PVS). He developed intracranial haemorrhage two years ago and has been unconscious since the episode. One year later, several specialists diagnosed him to be PVS. His chance of ever regaining consciousness is considered extremely slim. The only treatment the patient is currently receiving consists of fluid and nutrition through gastrostomy. His medical condition is stable and the estimated length of life is at least five years.

The first three vignettes differed as to whether the patient's prior wishes were known and whether family members were available for consultation. The fourth one asked the subject physicians what they would want for themselves in the circumstances described. The four vignettes comprised the following:

1. No verbal or written advance directives of any kind regarding patient wishes; patient has no family.

2. No verbal or written advance directives of any kind regarding patient wishes; family want to stop treatment which prolongs the life of the patient.

3. Patient did not want to be kept alive; family wants to stop treatment which prolongs the life of the patient.

4. If you were the patient described above, what would you want for yourself?

The vignettes also differed as to whether the patient was stable, whether he/she developed pneumonia, or whether he/she had respiratory failure. As a result, there were 12 variations in our cases. After each vignette, the following four possible responses were listed:

A. Stop all treatments necessary for prolonging life, including ANH.

B. Continue $\mathrm{ANH}$, but do not add any additional treatments or procedures.

C. Continue ANH, and add necessary treatments or procedures if necessary for prolonging life.

D. Other.

To ensure comparability of responses, we provided criteria for determination of PVS described in Merritt's Textbook of Neurology, ninth edition. ${ }^{10}$ The second part asked for the subjects' perception of the possibility of recovery of PVS patients; what would affect their decisions about treatment, and to what extent they thought the dignity of PVS patients as persons was offended. In the last part of the questionnaire, we collected demographic data including age, sex, specialties, and experiences of the care of a PVS patient.

\section{Data analysis}

The $\chi$-square test for independence was used to test differences between two independent categorical variables. The McNemer's $\chi$-square test for changes was used to test differences in attitudes of the respondents depending on given situations. A p value less than 0.05 was considered significant. Bonferroni's inequality was employed to determine cutoff value of statistical significance when multiple comparisons were made. For example, a $p$ value less than 0.0083 was considered when a six-comparison per one variable was made. 
Table 1 Characteristics of respondents

\begin{tabular}{ll}
\hline Total number & 190 \\
\hline Mean (range) age (yr) & $52(32-74)$ \\
Men (\%) & $187(98 \%)$ \\
Specialty (\%) & $75(40 \%)$ \\
Neurology & $85(45 \%)$ \\
Neurosurgery & $19(10 \%)$ \\
Internal medicine & $11(5 \%)$ \\
Others & $27(10-51)$ \\
Mean (range) practice experience (yr) & $22(12 \%)$ \\
Number (\%) with religious beliefs & $177(93 \%)$ \\
Experience with the care of a PVS patient & \\
\hline
\end{tabular}

\section{Results}

\section{CHARACTERISTICS OF RESPONDENTS}

Of the 317 subjects surveyed, 201 (65\%) returned their questionnaires; 190 respondents completed them. We analysed these 190 completed questionnaires. Demographic characteristics of the respondents are summarised in table 1 . The respondents were predominantly male and $93 \%$ had been involved in the care of PVS patients.

\section{DECISIONS OF RESPONDENTS TO HYPOTHETICAL} VIGNETTES

Table 2 shows the responses to the four case vignettes with $95 \%$ confidence intervals $(95 \%$ CI). Proportions listed in table 2 represent overall treatment-limiting decisions including withdrawal of $\mathrm{ANH}$, withholding antibiotics, and withholding mechanical ventilation.

In variation $1,3 \%$ of the respondents would withdraw ANH when the patient did not require any other life-sustaining treatments (LST), $4 \%$ would discontinue ANH and $30 \%$ would withhold antibiotics when the patient developed pneumonia. Six per cent of them would discontinue $\mathrm{ANH}, 28 \%$ would withhold antibiotics, and $47 \%$ would withhold mechanical ventilation when the patient developed respiratory failure. In varia $\underset{F}{F}$ tion $3,17 \%$ of the respondents would withdrav ANH when no other LST were required, $18 \%$ would withdraw $\mathrm{ANH}$ and $53 \%$ would withhol antibiotics when the patient developed pneumo? nia. Twenty-one per cent would discontinue ANH, $44 \%$ would withhold antibiotics, and $28 \%$ would withhold mechanical ventilation when the patient developed respiratory failure.

All proportions of overall treatment-limiting decisions in variation 3 are significantly higher than those in variation 1 ( $\mathrm{p}$ is less than 0.0001 ). I $\overrightarrow{8}$ variation 2 , family wishes alone did not influence respondents' decisions over withdrawal of ANH In variation 4 where they themselves were in thi PVS, significantly more respondents would be willing to withdraw $\mathrm{ANH}$, withhold antibiotics and mechanical ventilation than in all other varias tions ( $p$ is less than 0.0001 in all interventions).

EXPERIENCES OF THE RESPONDENTS IN REGARD TO THE CARE OF PVS PATIENTS

The questionnaire asked the respondents whether they had ever been requested to withdraw withhold LST by family members of PVS patients of whom they took care. Seventy-seven per cent (95\% CI: 74-80) of the respondents reported that they had been asked to withhold cardiopulmonar resuscitation (CPR) and 73\% (95\% CI: 70-76 had been required to withhold haemodialysis and/or mechanical ventilation. They had also beep required to withhold antibiotics $(22 \%, 95 \% \mathrm{CB}$ 19-25) and to withdraw ANH $(30 \%, 95 \%$ C 26-34). The frequency of the request made by the family members to withhold CPR, haemodialysis and mechanical ventilation was significantl higher than for $\mathrm{ANH}$ and antibiotics ( $\mathrm{p}$ is less thap 0.0001 ).

Table 2 Responses (\%) to the vignettes $(N=190)$

\begin{tabular}{|c|c|c|c|c|c|}
\hline \multirow[b]{2}{*}{ Variation } & \multirow[b]{2}{*}{ Patient's previous wishes } & \multicolumn{4}{|c|}{ Treatment-limiting decisions } \\
\hline & & Family's wishes & Withdraw $A N H^{*}$ & $\begin{array}{l}\text { No treatment for } \\
\text { pneumonia }\end{array}$ & $\begin{array}{l}\text { No treatment } \\
\text { for RF\# }\end{array}$ \\
\hline $\begin{array}{l}1 \\
2 \\
3 \\
4\end{array}$ & $\begin{array}{l}\text { Unknown } \\
\text { Unknown } \\
\text { No LST } \\
\text { If the respondents were in PVS }\end{array}$ & $\begin{array}{l}\text { Unknown } \\
\text { No LST } \\
\text { No LST }\end{array}$ & $\begin{array}{l}3(2-4) \\
6(4-8) \\
17(14-20) \\
40(36-44)\end{array}$ & $\begin{array}{l}34(32-37) \\
56(52-60) \\
71(68-74) \\
70(67-73)\end{array}$ & $\begin{array}{l}81(78-84) \\
95(93-97) \\
93(92-95) \\
95(92-97)\end{array}$ \\
\hline \multicolumn{6}{|c|}{ 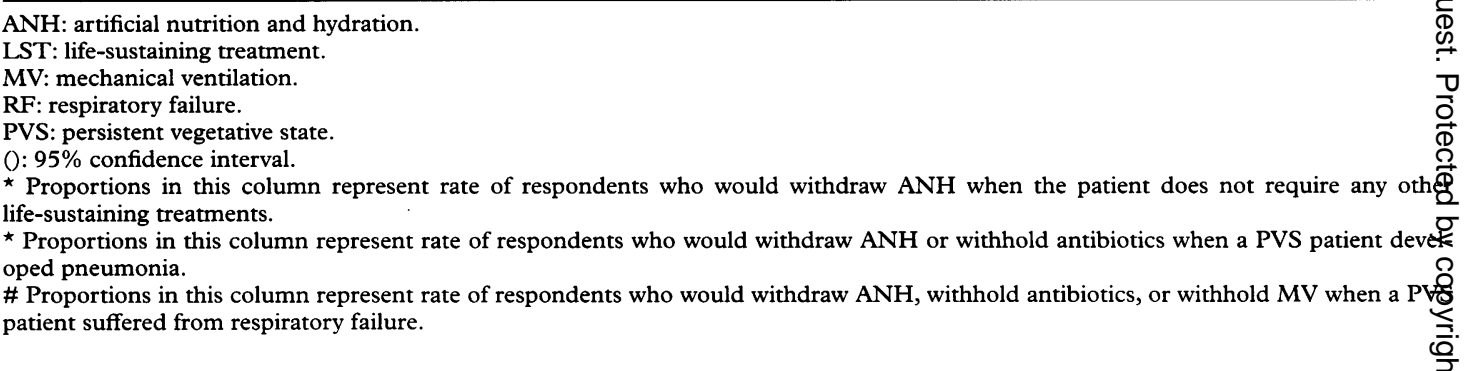 } \\
\hline
\end{tabular}


We also asked the respondents whether they had ever considered withdrawal and withholding of LST in the care of PVS patients. Eighty-two percent (95\% CI: $79-85)$ and $74 \%$ (95\% CI: 71-77) had considered withholding of CPR and hemodialysis and/or mechanical ventilation respectively. On the other hand, $31 \%$ (95\% CI: 27-35) and $16 \%$ (95\% CI: 13-19) had considered withholding antibiotics and withdrawing $\mathrm{ANH}$ from a PVS patient. Significantly more respondents had considered withholding CPR or haemodialysis and/or mechanical ventilation than antibiotics or ANH ( $p$ is less than 0.0001). In addition, significantly fewer respondents had thought of discontinuation of ANH than withholding of antibiotics ( $\mathrm{p}$ is less than 0.0001 ).

DIGNITY AS A PERSON, BRAIN DEATH, POSSIBILITY OF RECOVERY, AND ADVANCE DIRECTIVES

We asked the respondents to what extent they thought the dignity of PVS patients as persons was offended. Twenty-two per cent (95\% CI: 19-25) of them answered that their dignity as persons was not offended at all, $25 \%$ (95\% CI: 22-28) thought their dignity as persons was slightly offended, $38 \%$ (95\% CI: 35-41) considerably offended, and 15\% (95\% CI: 12-18) severely offended. Seventy-five per cent (95\% CI: 72-78) of the respondents considered that brain death meant death of a human being, 14\% (95\% CI: 11-17) were unsure, and $11 \%$ (95\% CI: 9-13) answered that brain death did not mean death of a human being.

The questionnaire also elicited the respondents' estimation of the possibility of recovery of PVS patients. Forty-three per cent (95\% CI: $39-47)$ of the respondents thought PVS patients would never recover, 52\% (95\% CI: 48-56) answered that one out of ten such patients or fewer would recover, and 3\% (95\% CI: $2-4)$ said one of five such patients could recover from their unconscious states.

Ninety-one per cent (95\% CI: $89-93 \%$ ) of the respondents thought patients' written advance directives expressing unwanted LST would influence their decisions; $73 \%$ (95\% CI: 70-76) considered oral advance directives not to provide LST would influence their decisions; $76 \%$ (95\% CI: 73-79) considered families' wishes not to provide LST would influence their decisions. Significantly more respondents regarded patients' written advance directives as influencing their decisions than oral advance directives $(91 \% \mathrm{v}$ $73 \%$, $\mathrm{p}$ is less than 0.0001 ). Of the respondents, $82 \%$ (95\% CI: $79-85$ ) had no experience of caring for PVS patients who left any form of advance directives, and 15\% (95\% CI: 12-18) had experience of fewer than ten patients who left advance directives, and 3\% (95\% CI: $2-4$ ) had experience of between 10 and 100 such patients.

FACTORS INFLUENCING ATTITUDES OF THE RESPONDENTS

Some attitudes and experiences of the respondents were related to their decisions with regard to the care of PVS patients. Respondents' specialties, experience of care of such patients, experience of PVS patients who left any form of advance directives, and perception regarding possibility of recovery were mutually statistically independent.

Significantly more respondents who regarded brain death as a human death tended to regard the dignity of PVS patients as persons offended, than those who regarded brain death otherwise $(86 \% \mathrm{v}$ $65 \%, p=0.013$ ). However, the attitude towards brain death itself was independent of the respondents' treatment-limiting decisions. Perceiving the dignity of PVS patients as offended also related to only one of 12 treatment-limiting decisions: those who regarded the dignity of PVS patients as being impaired were more willing to withhold mechanical ventilation in variation 1 than those who saw it as being unimpaired ( $86 \%$ v $65 \%, \mathrm{p}=0.003)$.

Experience of care of PVS patients was related to unwillingness to terminate LST. The respondents who had experience of caring for PVS patients were more likely to hesitate over withdrawing $\mathrm{ANH}$ in variation $2(4 \% \mathrm{v} 38 \%, \mathrm{p}=$ $0.00001)$ and in variation $3(18 \% \mathrm{v} 38 \%, \mathrm{p}=$ 0.04 ) than those who had no such experience. Those who thought that PVS patients had no chance of recovery were more willing to discontinue ANH $(11 \%$ v $3 \%, \mathrm{p}=0.046)$, withhold mechanical ventilation $(99 \% \mathrm{v} 92 \%, \mathrm{p}=0.033)$ in variation 2 , and withhold mechanical ventilation in variation $3(98 \% \mathrm{v} 89 \%, \mathrm{p}=0.03)$.

Attitudes of the respondents regarding oral advance directives and families' wishes were related to their overall treatment-limiting decisions in the vignettes. The respondents who answered that oral advance directives of their patients expressing the wish not to undergo unwanted LST would influence their decisions were more willing than those who answered otherwise, to discontinue $\mathrm{ANH}$ in variation 3 $(23 \% \mathrm{v} 2 \%, \mathrm{p}=0.0008)$. Those who responded that families' wishes not to provide LST would influence their overall treatment-limiting decisions, were also willing to withdraw $\mathrm{ANH}$ in variation $2(8 \% \mathrm{v} 0 \%, \mathrm{p}=0.045)$.

\section{Discussion}

Comparisons between the attitudes of the respondents in our study and those of physicians in the United Kingdom and the United States show 
striking differences. On the one hand, position papers of medical societies in these countries show that they endorse discontinuation of $\mathrm{ANH}$ as ethically appropriate. ${ }^{11}{ }^{12}$ Half of the United States physicians surveyed thought that PVS patients should be considered dead. ${ }^{8}$ A majority of these physicians would not want to live if they were in PVS. For instance, several studies showed that only about ten per cent of physicians and ethics consultants would want to have ANH if they were in PVS. ${ }^{813}$ On the other hand, in our study, few respondents would withdraw ANH from a PVS patient even if the patient had expressed his or her wish for that to happen and the patient's family agreed with the desire of the patient as specified in an advance directive. Furthermore, the majority of the respondents said that if they themselves were in PVS they would want ANH to be continued. The proportion of the respondents who would not want to have ANH provided for themselves and the proportion of the general public who would not want to have ANH provided might not be significantly different. ${ }^{9}$ It seems that both a majority of physicians and the general public in Japan would not be willing to withdraw LST, including $\mathrm{ANH}$, from PVS patients and would not want LST, including ANH, withdrawn from themselves if they were in PVS.

Why are Japanese physicians unwilling to terminate life-support for PVS patients? The authors believe that the most significant underlying reason is the concept the Japanese have in terms of the death of a human being. In the traditional Western ethic, the sanctity of life doctrine that life is a divine gift, given and sustained by God is predominant. Those who hold the doctrine would be reluctant to terminate the care of PVS patients. Physicians and patients' family members who are vitalists would think that the preservation of life in PVS is an end in itself, regardless of the quality of life. On the other hand, in Japan, where people have not been under the strong influence of Judaeo-Christianity, the extreme unwillingness of Japanese physicians regarding discontinuation of care for PVS patients is not explained by the doctrine. Together with the combined influence of Buddhism and Confucianism, Shintoism, which governs Japanese spirituality, long ago established the Japanese view of death: death is a curse, the corpse is polluting, and the spirit of the deceased is frightening. ${ }^{14}$ Life and this world have been highly valued and death has been denied and abhorred. Japanese seldom consider death as an invitation from the Creator. ${ }^{15}$ This abhorrence of death could still reside in the mind of the Japanese and might facilitate reluctance towards any kind of termination of life.
Some Japanese, including experienced physicians might not accept the concept that PVS patien are no longer persons. They would think that regardless of current consciousness, PVS patien still remain the same persons who had live meaningful lives with their families. They may nof accept that consciousness is a prerequisite for having an interest in or receiving benefit from medical intervention and that life prolongation of permanently unconscious patients can be $\mathrm{r} \overrightarrow{0}$ garded as futile. Furthermore, some Japanese might not accept discontinuation of life suppofe for irreversibly unconscious patients even if the regard such patients as not being persons an more. They may argue that human values do nơ rely on personhood or functioning as a persorf They may see existence itself as valuable: after alf the PVS patient has warmth and a pulse and engenders sympathy in them. Even permanent loss of consciousness could not, for these peoplos deprive PVS patients of the most importan element of a human being, although what that is not clear. This would follow the denial of the judgment that sustaining a mere biological life 8 futile and disproportionate to the cost or resources. Therefore, the care of PVS patients is no non-beneficial because prolonging their lives is worthwhile goal and therefore not just a pointles effort. This Japanese concept of life and death ma contribute to the respondents' reluctance to forgo any LST for such patients.

Second, some Japanese physicians think the primary obligation is to prolong the life of $\frac{\mathrm{F}}{\mathrm{g}}$ patient under any circumstances. Some think that if it becomes too easy to terminate LST, either i the name of rational treatment or patient selfo determination, it may lead to a gradual erosion respect for the life of patients. It is also pointed ou that some Japanese physicians tend to think that the way to act in the best interests of a patient is t 8 provide the best possible care at any stage of disease. ${ }^{16}$ This attitude would easily lead to the. belief that withdrawal of ANH, which inevitables causes a patient's death, is never ethicallit acceptable. ${ }^{17}$

Third, fear and anxiety of a lawsuit filed by the patient's family for murder may foster ther unwillingness to forgo LST for PVS patients. pointed out, it is the doctor who is ultimately of the line for medical liability, not other medical professionals; physician-family consensus may bE the most important determinant as to whether of not a patient's advance directives will be followe because a patient's surviving family members arg perceived by doctors as potential plaintiffs. ${ }^{18}$ In fact, a recent study done in Japan suggested that considerable number of physicians fear, or ats 
anxious about, lawsuits for murder when they consider withholding and withdrawal of LST from terminally ill patients. ${ }^{19}$ Even if Japanese physicians thought continuation of mere biological life was meaningless, the fear of a lawsuit could keep them from terminating that life.

Fourth, the perceived possibility of recovery from vegetative state could make Japanese physicians reluctant to forgo LST for PVS patients. Some physicians declared that they were never certain that PVS patients would never recover from their unconscious state. ${ }^{17}$ This view is shared by many of the patients' families. As our study suggests, families seldom request their physicians to withdraw ANH from PVS patients. A previous survey, done in neourosurgery departments, also demonstrates that it is extremely rare for a patient's family actually to ask the patient's physicians to withdraw ANH from a PVS patient even if that would be in accord with the patient's previously expressed wishes or the patient's own desire for death with dignity. The survey also showed that no physician had ever withdrawn ANH from a PVS patient. ${ }^{20}$

The findings of this study suggest that many Japanese physicians share the belief that life prolongation of permanent unconscious patients could be a goal of medicine and that it is not futile. However, unconditional and unlimited prolongation of PVS patients' lives poses many problems. Patients may not want to live in PVS. As shown by a public opinion poll, at least a quarter of the general public and $40 \%$ of our respondents do not want to be sustained in PVS. Despite the relatively low cost of medical care in Japan, some families may think that caring for such a patient is financially, as well as emotionally, too burdensome. ${ }^{21}{ }^{22}$ Therefore, preserving the life of PVS patients without critical evaluation would result in insensitive overriding of the patients' wish to die with dignity as persons rather than continue their biological existence. Such preserving would also result in suffering for the patients' families, both psychological and financial.

As far as resource allocation is concerned, even if all individuals involved in the care of PVS patients agree with life prolongation, there remains the ethical problem of justice. In the context of scarce medical resources and national health care systems, the principle of justice requires consideration of the opportunity cost both to potential recipients of the resource and to those who provide the funding for it, either through taxes or through insurance premiums. ${ }^{23}$ Individuals who regard the prolongation of a mere biological life as meaningless would consider that expenditure of significant resources on such care is unacceptable. On the other hand, some individuals, including some of our respondents, would argue that the benefits of the care justify the cost. It may be that this dispute cannot easily be resolved by rational discussion. A question about what kind of life is valuable is essentially a matter of definition and must form the basis of further moral thinking. Also it is an assumption that cannot be fully defended because it is fundamental. ${ }^{24}$ Nevertheless, the general public, families of PVS patients, and physicians should continue deliberating over the best way to proceed in this matter, for this is something that affects everyone in a society. The authors believe that the family's wish to keep a PVS patient alive should be respected in general, but, at the same time, that the family's wishes should not be considered absolute. Medical resources are always limited and have to be used carefully. Therefore, in certain situations, such wishes could be overridden. So far there has been no consensus in this regard in Japan, but any solution will have to be a principled one that applies generally and it will have to be arrived at by consensus. ${ }^{25}$

This study has several limitations. The generalisability of our results is limited. Because the physicians surveyed were members of one association, they may not be representative of others involved in the care of PVS patients. The respondents were predominantly men and thus the results do not represent attitudes of female physicians in Japan. A report of the Ministry of Health and Welfare showed that $11.9 \%$ of all Japanese physicians were women in 1992 and only eight per cent were working in national hospitals or medical institutes in $1995 .^{26}$ Female respondents in this study accounted for only two per cent of all respondents. In addition, more than one-third of our subjects did not participate in our study and their attitudes may differ from those who participated. They could be more conservative in the care of PVS patients, although there is no evidence in this regard. It should also be noted that answers to the questionnaire might not necessarily reflect the respondents' actual behaviour in the care of PVS patients. It should also be pointed out that attitudes reported by the respondents were based on a case of a male PVS patient in his 70s who had been unconscious for two years. In addition, in the given vignettes, we assumed no disagreement regarding decisions over LST among people involved in the case. Therefore, responses could have differed significantly if the PVS patient in the vignettes had been younger, as were Karen Ann Quinlan, Nancy Cruzan and Anthony Bland. ${ }^{6}{ }^{27}$ It is also possible that respondents' decisions might be different if family members in the vignettes 
desired to prolong the life of the patient, as in the case of Helga Wanglie. ${ }^{27}$

In conclusion, this study shows that Japanese physicians are very reluctant to abandon life prolongation for PVS patients. Patients' advance directives and the desires of their families could, however, have some impact on physicians' decisions. Current practice is certainly grounded in the deep-rooted concept of life and death in Japanese culture, but unconditional and unlimited continuation of the life of PVS patients could result in imposing unwanted treatments on patients or their families and the financial collapse of health care. Therefore, it is urgent for the Japanese people as a whole to discuss what is the goal of medicine, what constitutes the best care of unconscious patients, and what kind of life we want to live.

\section{Acknowledgement}

This study was supported by the Grant for Scientific Research expenses for Health and Welfare Program; Funds for Comprehensive research on Long Term Chronic Disease (Renal Failure).

Atsushi Asai, MD, MBioeth, is Lecturer in the Department of General Medicine and Clinical Epidemiology, Kyoto University School of Medicine, Kyoto, fapan and at the Centre for Human Bioethics, Monash University, Melbourne, Australia. Munetaka Maekawa, MD, is Research Assistant in the Division of Health Information and Science, Kobe University Research Center for Urban Safety and Security, Kobe, Fapan. Ichiro Akiguchi, MD, is Associate Professor in the Department of Neurology, Kyoto University School of Medicine, Kyoto. Tsuguya Fukui, MD, MPH, is Professor in the Department of General Medicine and Clinical Epidemiology, Kyoto University School of Medicine, Kyoto. Yasuhiko Miura, MD, is Assistant Professor in the Department of Internal Medicine, the fikei University School of Medicine, Fikei, Fapan. Noboru Tanabe, MD, is a Graduate Student at the Kyoto University School of Law, Kyoto. Shunichi Fukuhara, MD, MSc, is Assistant Professor in the Department of Internal Medicine, Division of Medical Science, Graduate School, the University of Tokyo Faculty of Medicine, Tokyo. Address correspondence to: Atsushi Asai, MD, MBioeth, Department of General Medicine and Clinical Epidemiology, Kyoto University School of Medicine, 54 Shogoin Kawaharacho, Sakyo-ku, Kyoto, Japan. Post code: 606-8507; tel: 81-75-751-4210; fax: 81-75-751-4211.

\section{References}

1 Andrews K. Patients in the persistent vegetative state: problenn in the long term management. British Medical fourn 1993;306:1600-2.

2 Gillon R. Patients in the persistent vegetative state: a respon to Dr Andrew. British Medical fournal 1993;306:1602-3.

3 Emanuel LL, Barry MJ, Stoeckle JD, Ettelson LM, Emanu EJ. Advance directives for medical care - a case for greater us New England fournal of Medicine 1991;324:889-95.

4 The SUPPORT investigators. A controlled trial to impro care for seriously ill hospitalized patients. Journal of the Amena
can Medical Association 1995;274:1591-8.

5 Frankl D, Oye RK, Bellamy PE. Attitudes of hospitalized patients toward life support: a survey of 200 medical inpatients. American fournal of Medicine 1989;86:645-8.

6 Singer P. Rethinking life and death: the collapse of our tradition $\overrightarrow{6 P}$ ethics. Oxford: Oxford University Press 1994.

7 Grubb A, Walsh P, Lambe N, Murrells T, Robinson S. Surve of British clinicians' view on management of patients in persis ent vegetative state. Lancet 1996;348:35-40.

8 Payne K, Taylor RM, Stocking C, Sachs GA. Physicians attitudes about the care of patients in the persistent vegetatife state: a national survey. Annals of Internal Medicine 1996;125 104-10.

9 Report from a survey of the fapanese general public regarding their preferences towards terminal care. Tokyo: Division of Publit Policy, Ministry of Health and Welfare, 1994 (in Japanese). 10 Rowland LP. Merritt's textbook of neurology [9th ed]. Baltimors Williams and Wilkins, 1995: 26.

11 Institute of Medical Ethics Working Party on the Ethics of Pros longing Life and Assisted Death. Withdrawal of life-suppoon from patients in a persistent vegetative state. Lancet 1991; 337; 96-8.

12 American Neurological Association Committee on Ethic $\$$ Affairs. Persistent vegetative state: report of the American Neurological Association Committee on Ethical Affairs. Annots of Neurology 1993;3:387-9.

13 Fox E, Stocking C. Ethics consultants' recommendations fo life-prolonging treatment of patients in a persistent vegetatig state. Fournal of the American Medical Association 1993;270 2578-82.

14 Young KK. Death: Eastern thought. In: Reich WT, ed. Encyc $\$$ pedia of bioethics [revised ed]. New York: Macmillan Reference Library, 1995: 487-97.

15 Kodera S. Nippon-jin no seimei-kan. In: Tsukazaki T, Kam $\mathrm{N}$, eds. Seimei-rinri no genzai. Kyoto: Sekaisiso-sha, 198951-69 (in Japanese).

16 Tatara K. On putting life first. Lancet 1995;346:327-8.

17 Tsukamoto Y. Patient's autonomy vs doctor's ethical integriry. fournal of fapan Association for Bioethics 1996;6:22-6 (面) Japanese).

18 Deal SJ. Are doctors ignoring living wills? Pennsylvan Medicine 1996; Dec:34-7.

19 Asai A, Miura Y, Tanabe N, Fukuhara S, Kurihara M. Advan directives and other medical decisions concerning the end of life in cancer patients in Japan. European Fournal of Cance 1998; 4: 582-6.

20 Tsukamoto Y. Kanja no jokoketteiken to iryosha no ryosinnte kyohi. Nenpo Iji Hogaku 1994;9:22-9 (in Japanese).

21 Asai A, Fukuhara S, Inoshita O, Miura Y, Tanabe N, Kuroka $\mathrm{K}$. Medical decisions concerning the end of life: a discussion with Japanese physicians. Fournal of Medical Ethics 1997;2R 323-7.

22 Ikegami N, Campbell J. Medical care in Japan. New Englaind fournal of Medicine 1995; 333:1295-9.

23 Gillon R. Persistent vegetative state and withdrawal of nutritiof and hydration. Fournal of Medical Ethics 1993;19:67-8.

24 Morreim EH. Profoundly diminished life: the casualties coercion. Hastings Center report 1994;24:33-42.

25 Angell $M$. The case of Helga Wanglie: a new kind of "right die" case. New England fournal Medicine 1991;325:511-12. (

26 Simazaki A. Support systems are essential for women to become doctors. Medical Education (fapan) 1996;27:73-6 (im Japanese).

27 McIntyre RL. The significance of the legacy of Karen Ar Quinlan. Trends in Health Care, Law and Ethics 1993;8:7-19. ๑ 